\title{
Key Performance Indicators at manufacturing workflow in specific medical devices: A Systematic Literature Review
}

\author{
Garnica-Bohórquez, Israel ${ }^{1}$, López-Gualdrón ${ }^{2}$, Clara Isabel $^{3}$, Martínez-Gómez ${ }^{4}$, Javier \\ Mauricio 5 \\ Industrial Design School, Universidad Industrial de Santander, Bucaramanga, Colombia
}

\begin{abstract}
In the health sector, specifically by facture treatment, it is fundamental to understand clinical and technical requirements to provide a specific solution for patients and surgeons, mainly on complex procedures. But the human resource is dynamic in both, industrial an academical sectors. Usually, the knowledge has been constructed on iterative processes trough multidisciplinary approach that involve surgeons and designers. But often, collaboration work is conducted without conscious about metrics which could provide historical performance. This is essential to provide feedback in the process, to propose improvements, and also to enhance traceability and learning skills. In our context, it is crucial because of the need to provide affordable solutions by using scare resources. To start the design of a suitable strategy which faces those aims, first, we conducted a systematic review related to reported cases. We focusing on works were technological resources and multidisciplinary collaboration was essential for specific device development. A bibliometric study was conducted with 421 documents from PubMed and Web of Science. Then, 51 documents were selected to be exhaustively review, in order to understand patterns about performance. Finally, 5 documents were identified by snowball specifically related to Key Performance Indicators on different sectors where PLM strategy was applied, summarizing 169 KPIs. As a conclusion, the authors recommended implementing 8 KPIs in medical device development.
\end{abstract}

Keywords: Additive manufacturing, collaboration, key performance indicator, specific medical devices. 


\section{Introduction}

Morbidity rates are increasing according to the WHO, thus non-transmissible illness will represent $60 \%$ of traumas by 2020 (WHO, 2017). Healthcare cost will be a fiscal burden by 1 to $3 \%$ in GDP in many countries, mostly by traffic accidents. MD have been produced mostly for fracture treatment, oncology or congenital issues. Trauma affects the youngest adults by traffic or labor accidents, and the oldest for failings, demanding high healthcare burden. Although epidemiologic data depends on local registers, cranial contusions have prevailed from $33 \%$ to $47 \%$ of all cases (Alberdi, García, Atutxa, \& Zabarte, 2014). Normally, bone resection must be performed intraoperatively as a part of a treatment, to restore bone function, fracture reduction and aesthetic. As well as traumatic defects, oncology and congenital defects could affect bone structures. So, physicians have the challenge to do restauration accurately as possible, preserving unaffected tissue and organs. For improving medical praxis and reducing mistakes, they need technical aids called medical devices MD to translate their planning to the operating theater.

Despite MD are a vast sort of artifacts (Santos, Gazelle, Rocha, \& Tavares, 2012), our interest lies upon orthopedic MD and how that objects could be properly done. Orthopedic restauration could be done by a craft bone from a cadaveric donor, by autologous bone using vascularized tissue from the patient's body, or a synthetic implant if a large defect is involved (Logeart-Avramoglou, Anagnostou, Bizios, \& Petite, 2005). Usually Physicians use 2D images from computed tomography CT to diagnosis. But, 3D conversion and design with computeraided techniques CAx (Salonitis \& Stavropoulos, 2013) have been adopted as valuable tools to reduce uncertainty.

Thus, is possible to define surgical steps previosly, and fabricate patient-specific MD such as biomodels, cutting-drilling guides, and patient-specific implants PSI (FDA, 2018) by means of rapid prototyping RP, using sustractive or additive manufacturing SM-AM. Many alternatives are available, but depending on the context those are not affordable. Altough the USA and Europe drive the global market, countries like Mexico and Brazil have reported an increasing in MD fabrication(Maresova, Penhaker, Selamat, \& Kuca, 2015). That is because MD produced by the scale in developed countries are not suitable for specific population needs (WHO, 2003) enhancing the need to improve quality control and technology appropriation, which represents a great opportunity for developing countries (Ishengoma \& Mtaho, 2014).

On the other hand, results that fit user's requirements are possible just for multidisciplinary collaboration (Larsson et al., 2003), despite the kind or cost of tools involved. In this case, deeplly understanding of surgeon needs could save a lot of effort.

Thus, to achieve product requirements is essential to control the MD development (Hieu et al., 2010). Collaboration depends on skills shared by the team. To make accurate decisions, somo methods like Product life-cycle management PLM has shown relevance. PLM focus on governing technical documents, roles, stages, and tools by assuring integration, control, security, and traceability of data (Lantada \& Morgado, 2013). Thus, a workflow compromises people and resources to control inputs/outputs. That could be measure by key performance indicators KPIs (Cable, Hoc, \& Management, 2005), metrics asociated with a process that stablish a baseline to follow up. But first, it is necesarry to identify them. 


\section{5th International Conference On}

\section{Modern Approaches in SCIENCE, TECHNOLOGY \& ENGINEERING}

\section{9 - 31 August, 2019 \\ Germany, Berlin}

To face those problems, a systematic literature review was conducted in order to identify key performance indicators KPIs, focusing on data related to the process of specific patient treatment by using technology. Following sections describe the methodology, results, and final conclusions.

\section{Methodology}

To proceed with the systematic review, a bibliometric analysis was conducted, then a content analysis and finally a snowball process to identified the KPIs. The entire procedure is related in Figure 1. Two questions were formulated to be solved: which key performance indicators related whit cost, time and quality could allow manufacturing capabilities in specific MD development? And there is a consensus about workflow? First, an exploratory thesaurus list was constructed looking for non-covered reviews for terms like "3D printing, "KPI", and"workflow" on Prospero database (Booth et al., 2012).

Figure 1: The review process.

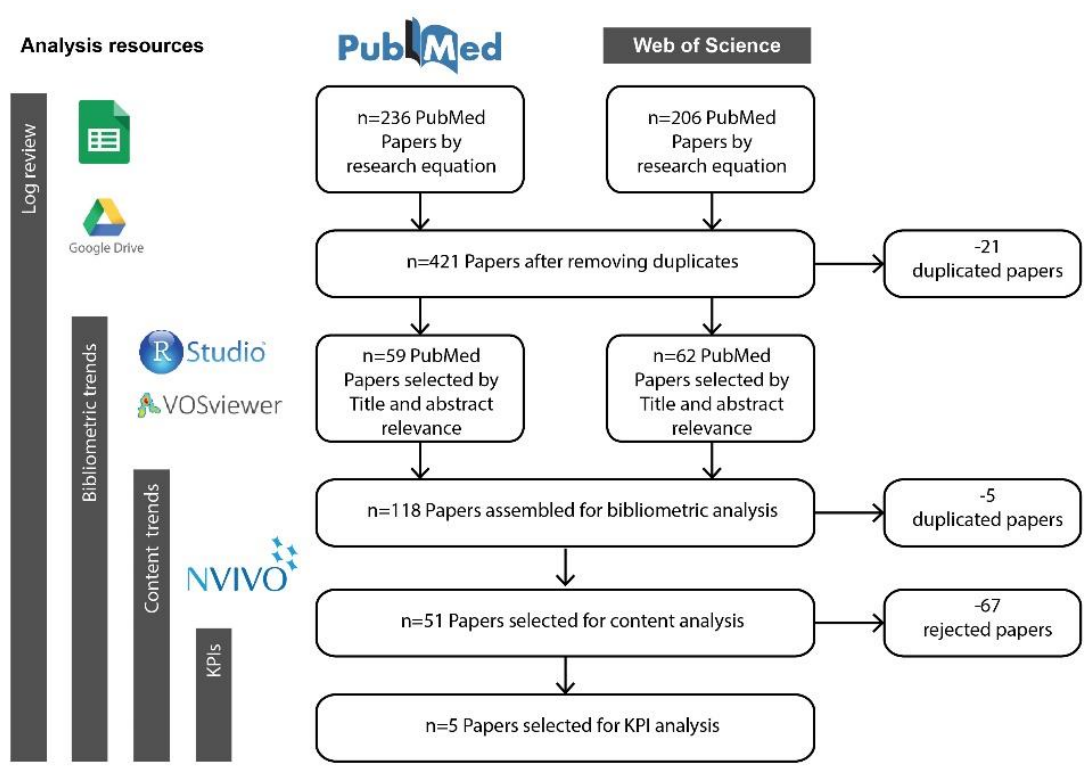

Source: By authors.

Thus, a research equation was designed by 370 different terms related to "3D printing"(24),“capability(6), "Manufacturing”(32),“collaboration”(20), “strategy"(24), "workfl ow"(60), "KPI"(66), "interoperability"(51),"trauma"(21),"device performance”(31), and "specific-medical device"(35). To avoid bias, anatomical zones were excluded from the research equation. Please see table 2, in Appendix I, which showed the constructed research equation. Two databases were selected due to their content quality papers, PubMed and Web of science. As inclusion criteria, only the papers written in English were selected, with content that showed quantitative or qualitative evidence in clinical trials for MD, published from 2010 to 2018. Papers non-related with clinical trials were excluded as well as literature reviews, reports, and book chapters. 


\section{5th International Conference On}

Modern Approaches in SCIENCE,

TECHNOLOGY \& ENGINEERING

\section{9 - 31 August, 2019}

Germany, Berlin

\section{Results}

Papers excluded in the title and abstract review were related to animal treatment, surgery protocols, bioprinting, tailored instruments, splints, cardiology and ophthalmology implants. To perform data analysis, results from both database were assembled, to use it as input for Vosviewer tool (van Eck \& Waltman, 2010) and bibliometrix (Aria \& Cuccurullo, 2017). In the first, clustering showed relevance from China and the USA as showed in Figure 2. In the second, a lokta distribution was observed in the sample, with a $\beta=3,8$ and a $p$ value $=0,21$ for the Kolmogorov-Smirnoff test.

Figure 2: Most productive countries in the field.
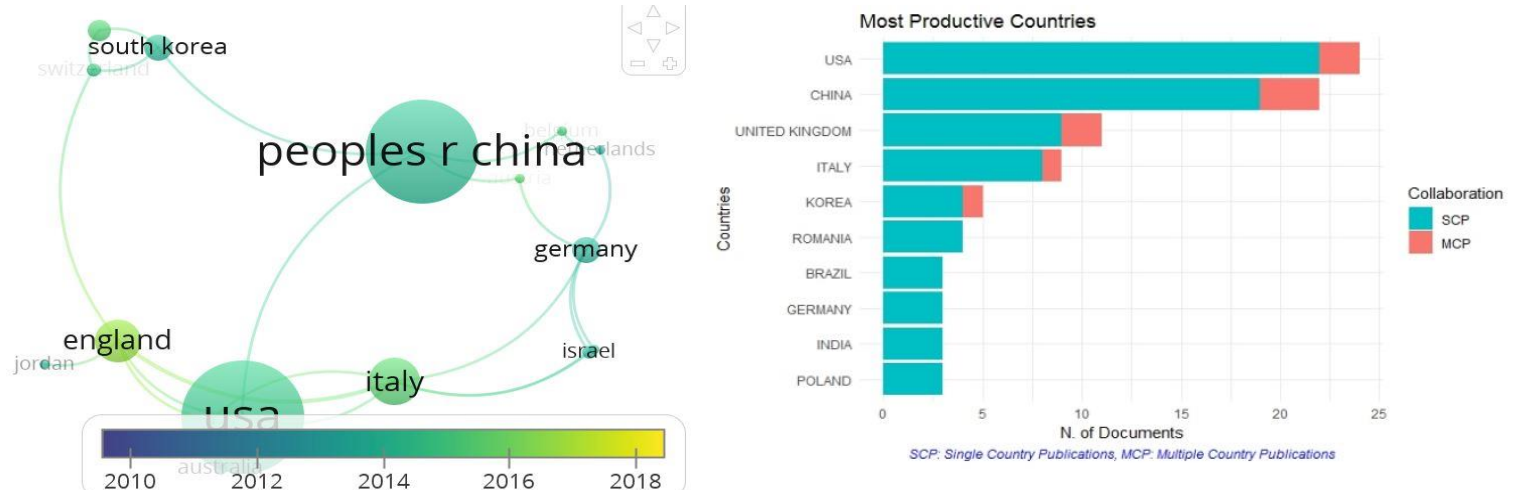

Source: By authors.

For the content review, being $\mathrm{N}=118$ papers, with a confidence level of $95 \%$ and the margin of error of $10 \%$, the sample size calculated was 51 papers. Papers related to esthetical implants, non-osseous implants, and old samples were omitted. Those papers were analyzed with Nvivo v12. Rather than previous results, 24 author's nationalities were observed, 23,5\% were from China, 11,8\% form Italy, 7,8\% from the United Kingdom, just 3,9\% from the USA, and $2 \%$ from Mexico. Those papers were mostly reported practical content $76 \%$, theoretical $18 \%$ and theoretical-practical $6 \%$. 


\section{5th International Conference On}

\section{Modern Approaches in SCIENCE, TECHNOLOGY \& ENGINEERING}

Figure 3. Clinical case frequency by anatomical zone.
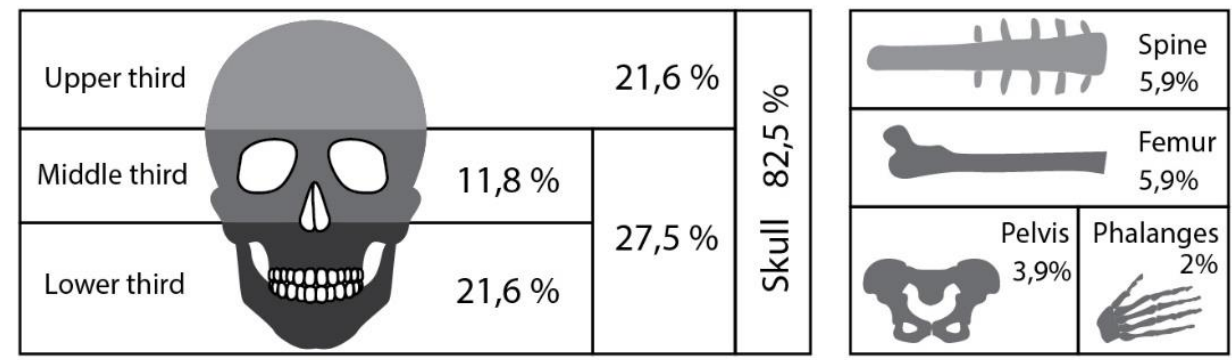

Source: By authors.

Study cases samples varied from 1 to 31 people, with an average age from 3 to 65 years, mostly by women $56 \%$. The sample etiology was mostly due by trauma $36 \%$, following by oncology pathologies $34 \%$, congenital defects $28 \%$ and arthrosis $2 \%$. Institutions characteristics were labeled as university hospital $33 \%$, hospital $16 \%$, university $47 \%$, and military hospital $4 \%$. Researches were conducted mostly by a department of cranio-maxillofacial surgery. That showed consistency for anatomical zone affected for pathology, mostly cases in the skull by $82,5 \%$, as showed in Figure 3.

Also was observed the kind of MD reported. Virtual surgical pre-planning was conducted in $94,1 \%$. A physical biomodel was required in $66,7 \%$. Permanent implants were setting on $52,9 \%$ of cases. A surgical guide was used in $43,1 \%$. Position guides were both used in $13,7 \%$. Technology integration was observed as well to help accelerating process. BIOCAD, CAD, and RP by AM were used in $94,1 \%$ cases. Reverse engineering RE was observed just by $27,5 \%$.

Computer aided engineering CAE analysis by $15,7 \%$. Computer aided manufacturing CAM by SM in $11,8 \%$. BIOCAD was commercial software in $72,5 \%$ of cases, open software in $13,8 \%$, and own development software by $3,9 \%$. Commercial CAD software was used by $49 \%$, educative licenses by $19,6 \%$, and open software by 7,8\%. RE software help designer to fix the virtual mesh, but just $9,8 \%$ reported its. Similarly, CAE software was used by $9,8 \%$. To manufacturing devices, by SM means, were reported molding 13,7\%, polishing 9,8\%, bending $9,8 \%$, CNC 7,8\%, casting 7,8\%, and sculpting 5,9\%. By AM means, metal printing DMLSSLS leads trend with $41 \%$, following for photo-polymeric resin that was used in $29 \%$, polymeric thread FDM by $22 \%$, and ceramic printing 3DP-BJ by $14 \%$. 


\section{5th International Conference On}

\section{Modern Approaches in SCIENCE, TECHNOLOGY \& ENGINEERING}

\section{9 - 31 August, 2019 \\ Germany, Berlin}

\section{Discussion}

Some authors reported a formalized workflow (Beer, 2013; Ejaz et al., 2014; Fang, Liu, Wu, Lee, \& Kuo, 2013; Kouhi, Masood, \& Morsi, 2008; McAllister, Watson, \& Burke, 2018; Mottini, Seyed Jafari, Shafighi, \& Schaller, 2016; Nasr, Al-Ahmari, Alkhawashki, Altamimi, \& Alkhuraisi, 2015; Rahmati, Abbaszadeh, \& Farahmand, 2012; Ruiz-Huerta, AlmanzaArjona, \& Caballero-Ruiz, 2016; Turgut, Özkaya, \& Kayal, 2012; Wong, Kumta, Gee, \& Demol, 2015). Authors reported its interest on virtual modelling (Bogu, Ravi Kumar, \& Khanara, 2017; Egger et al., 2017), steps for virtual reconstruction and manufacturing (Ciocca et al., 2015; Han et al., 2017; Nasr et al., 2015; Park et al., 2016), clinical process (Mazzoni, Bianchi, Schiariti, Badiali, \& Marchetti, 2015; Mottini et al., 2016), in-house capabilities (McAllister et al., 2018), and comparison between conventional and digital workflow (Peel \& Eggbeer, 2016; Ruiz-Huerta et al., 2016). Despite there is not a consensus about the workflow, we proposed one, based on the steps following by decisions in each phase of the life-cycle for MD development (Martiínez, López, Murillo, \& Garnica, 2019). Workflow is showed in figure 4. Next, the finding related to quality, cost and time was summarized.

Figure: 4. a common workflow observed in the literature review.

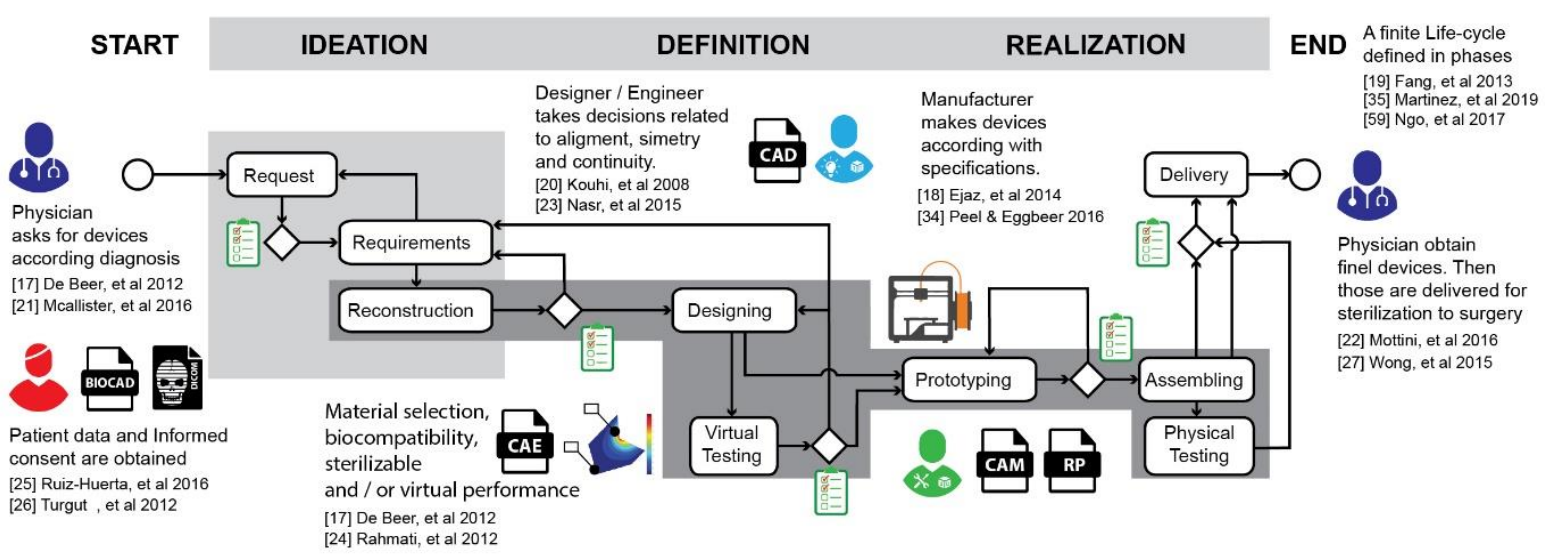

Source: By authors. 


\section{9 - 31 August, 2019 \\ Germany, Berlin}

\subsection{Manufacturing Capabilities}

Quality was commonly related after surgery to measure sensibility of pain (Cassetta, Altieri, Pandolfi, \& Giansanti, 2017; Hussein, 2013), symmetrical contour (Azuma et al., 2014; Hatamleh, Yeung, Osher, \& Huppa, 2017), patient and surgeon satisfaction (Kanno et al., 2016; Ortiz et al., 2012), aesthetics (Chrzan et al., 2012; Kaur et al., 2015), infection rate diminution (Park et al., 2016; Turgut et al., 2012), blood loss (Mendez, Chiodo, \& Patel, 2015; Wei, Guo, Ji, Zhang, \& Liang, 2017), functional recovery (Xu et al., 2016; Y. Zhang et al., 2018) and virtual comparison from virtual preplanning to result (Abdel-Moniem Barakat, Abou-Elfetouh, Hakam, El-Hawary, \& Abdel-Ghany, 2014; Yang et al., 2018; L. Zhang, Shen, Yu, Shen, \& Wang, 2015).

Some authors reported cost depending on their interest. A biomodel could be fabricated by less than $300 €$ (Kozakiewicz et al., 2009). Surgical guides for maxilla and biomodel cost would be 500 to $1000 €$ (Mazzoni et al., 2015). Implants, of course, are more expensive. An orbital implant could cost 2,000 to 14,000 USD\$ (Callahan, Campbell, Petris, \& Kazim, 2017). An skull implant could cost 300 to 1300 USD\$ (Chrzan et al., 2012) or 800 USD\$ (Goh, Chang, Lin, \& Lo, 2010). A mandible implant could cost 1500 to $3000 €$ (Gil et al., 2015), or 5000 to 7000 USD\$ (Ruiz-Huerta et al., 2016). Some authors compared inner with outsourcing cost. Thus, that could be reduced from 2000 to $1000 £$ (McAllister et al., 2018), from 1782 to $660 £$ (Peel \& Eggbeer, 2016) or 4000 to 25 USD\$ (Mendez et al., 2015).

Time as well depends on the author's interest. Comparing conventional techniques to RP, total treatment was reduced from 24 to 8 months (Cassetta et al., 2017), 7 to 6 days (Peel \& Eggbeer, 2016), even less than 48 hours (Mottini et al., 2016). Other looking for a reduction of intraoperative time (Chrzan et al., 2012) or saving time for use biomodels to pre-bent plates (Reiser et al., 2015). Other were focusing on time segmentation by BIOCAD, 2 hours average (Egger et al., 2017). However, exist drawbacks when metallic noise is on CT, taking between 18 to 22 hours per case (Kouhi et al., 2008). Although design time, 8 hours, could be less than manufacturing, 25 hours (Rahmati et al., 2012), other author reported that the entire project could be longer, 3 to 36 days, depending on complexity (McAllister et al., 2018), or 2-3 weeks by outsourcing and delivery (Mendez et al., 2015). Although development and design

time could be less than 30 hours, delivery could last 3,4 weeks (Yang et al., 2018) or 5-10 weeks if the request was into a developing country (Ruiz-Huerta et al., 2016).

\subsection{PLM in the Health sector}

In the systematic review conducted, the use of PDM software was observed in just 3,9\% of all cases. Despite benefits that PLM have promoted in different industrial sectors, is relative rare its implementation in the health sector. Zdravković, Trajanović, Stojković, Mišić, \& Vitković, 2012 identified interoperability as a crucial factor to reduce time and errors in PSI development. Allanic et al., 2015 proposed a commercial PDM implementation for an imaging laboratory with a lot of heterogeneous data and different roles involved. Popescu, Ilie, Laptoiu, Hadar, \& Barbur, 2016 had reported an ongoing web-based platform to support communication between actors in a PSI cranial treatment. Finally, Ngo, Belkadi, \& Bernard, 2017, had 


\section{5th International Conference On}

\section{Modern Approaches in SCIENCE,}

TECHNOLOGY \& ENGINEERING

\section{9 - 31 August, 2019 \\ Germany, Berlin}

formulated a PLM framework to support PSI development, keep data safely and support different roles involved in a workflow.

\subsection{KPI to control the process}

There are so many variables to take into account. But was necessary to identify them to set its relevance. However, it is recommended for management that the quantity of KPI might be between 7 to 12, grouped in 4 to 8 categories (Lavy, Garcia, \& Dixit, 2010). Just one paper, Peel et al (Peel \& Eggbeer, 2016) explicit mentioned KPI related to process development on PSI. They have identified 3 different manufacturing strategies for PSI fabrication, namely conventional, semi-digital and digital, comparing workflows, cost and time. It was proposed 41 KPIs, but, 3 mainly KPIs were highlighted: the number of design changes, fidelity on specifications, and routine adoption rate. Other authors explored by snowball were identified in different sectors. Alemanni et al (Alemanni, Alessia, Tornincasa, \& Vezzetti, 2008) proposed 47 KPIs for aerospace development grouped on 5 categories. Myung et al (Myung, 2018) projected 20 KPIs for naval design grouped in 3 categories. Stark (Stark, 2016) suggested 36 KPIs grouped in 4 categories in PLM implementation. Finally, Pinna et al (Pinna et al., 2018) advocated using 25 KPIs in the Food industry grouped in 4 categories. In total, 169 KPIs were analyzed and codified. Thus, in table 1, we proposed the most suitable KPIs to taking into account.

Table 1. Summary for KPIs proposed.

\begin{tabular}{|l|c|l|}
\hline Category & KPI & \multicolumn{1}{c|}{ Description } \\
\hline Time & 2 & $\begin{array}{l}\text { Developed time. From CT acquisition to surgical date. From CT arrive at medical device } \\
\text { delivery. }\end{array}$ \\
\hline Cost & 1 & Developing cost. The human resources, material and machine expenditures in a case. \\
\hline Quality & 5 & $\begin{array}{l}\text { The number of changes in a project. The percentage of requirement accomplished. Surgeon } \\
\text { satisfaction. CT resolution. 3D print resolution. }\end{array}$ \\
\hline
\end{tabular}

Source: By authors. 


\section{5th International Conference On}

\section{Modern Approaches in SCIENCE, TECHNOLOGY \& ENGINEERING}

\section{9 - 31 August, 2019 Germany, Berlin}

\section{Conclusion}

First, the systematic literature review allowed us to understand the different technological integrations that researchers have adopted during the design and development of specific MD such as biomodels, surgical guides, and implants, specifically for traumatic, oncology a congenital defects. Second, patterns about MD interest and tools integration showed RP importance in the field, been AM more adopted than SM. Third, PLM in health sector, regardless complexity of implementation, it would be a gap to explore in the health sector. Third, KPIs related to management capabilities, like delivery time, cost and quality have been observed in the MD process.

Even though some parameters in design could be an input for KPIs, like material mass for overall cost, the difference lies that KPIs are associated with corporative measurable goals, in order to monitoring causes and take decisions based on historical data from cases. Thus, based on the KPIs identified, we proposed 8 KPIs grouped on 3 categories to support metrics in specific MD development. Results will be applied in further works to define metrics in a PLM strategy for orthopedic treatment that depends on team work.

\section{Acknowledgment}

The authors wish to express their gratitude to research groups IINTERFAZ, GRICES, and INNOTEC at the Universidad Industrial de Santander, COLCIENCIAS (Department of Science, Technology and Innovation) and the Santander's Government, who provided their support.

\section{Disclosure}

The authors report no conflict of interest for economic, ethical or social topics in the present paper.

\section{References}

Abdel-Moniem Barakat, A., Abou-Elfetouh, A., Hakam, M. M., El-Hawary, H., \& Abdel-Ghany, K. M. (2014). Clinical and radiographic evaluation of a computer-generated guiding device in bilateral sagittal split osteotomies. Journal of Cranio-Maxillofacial Surgery, 42(5), 1-9. https://doi.org/10.1016/j.jcms.2013.08.007

Alberdi, F., García, I., Atutxa, L., \& Zabarte, M. (2014). Epidemiology of severe trauma. Medicina Intensiva, 38(9), 580-8. https://doi.org/10.1016/j.medin.2014.06.012

Alemanni, M., Alessia, G., Tornincasa, S., \& Vezzetti, E. (2008). Key performance indicators for PLM benefits evaluation: The Alcatel Alenia Space case study. Computers in Industry, 59(8), 833-841. https://doi.org/10.1016/j.compind.2008.06.003

Allanic, M., Hervé, P.-Y., Durupt, A., Joliot, M., Boutinaud, P., \& Eynard, B. (2015). PLM as a strategy for the management of heterogeneous information in Bio-Medical Imaging field. International Journal of Information Technology and Management, in press(1), 5-30. Retrieved from http://www.inderscience.com/info/ingeneral/forthcoming.php?jcode=ijitm

Aria, M., \& Cuccurullo, C. (2017). bibliometrix: An R-tool for comprehensive science mapping analysis. Journal of Informetrics, 11(4), 959-975. https://doi.org/10.1016/j.joi.2017.08.007

Azuma, M., Yanagawa, T., Ishibashi-Kanno, N., Uchida, F., Ito, T., Yamagata, K., ... Bukawa, H. (2014). Mandibular reconstruction using plates prebent to fit rapid prototyping 3-dimensional printing models ameliorates contour 


\section{5th International Conference On}

\section{Modern Approaches in SCIENCE, TECHNOLOGY \& ENGINEERING

deformity. Head \& Face Medicine, 10, 45. https://doi.org/10.1186/1746-160X-10-45

Beer, N. De. (2013). Patient-specific intervertebral disc implants using rapid manufacturing technology, 2(May 2012), 126-139. https://doi.org/10.1108/13552541311302987

Bogu, V. P., Ravi Kumar, Y., \& Khanara, A. K. (2017). Modelling and structural analysis of skull/cranial implant: Beyond mid-line deformities. Acta of Bioengineering and Biomechanics, 19(1), 125-131. https://doi.org/10.5277/ABB00547-2016-04

Booth, A., Clarke, M., Dooley, G., Ghersi, D., Moher, D., Petticrew, M., \& Stewart, L. (2012). The nuts and bolts of PROSPERO: an international prospective register of systematic reviews. Systematic Reviews, 1(2). https://doi.org/10.1186/2046-4053-1-2

Cable, J. H., Hoc, C. A., \& Management, A. (2005). Key Performance Indicators for Federal Facilities Portfolios. The National Academics os Sciences, Engineering and Medicine. https://doi.org/10.17226/11226

Callahan, A. B., Campbell, A. A., Petris, C., \& Kazim, M. (2017). Low-Cost 3D Printing Orbital Implant Templates in Secondary Orbital Reconstructions. Ophthalmic Plastic and Reconstructive Surgery, $X X(\mathrm{Xx}), \quad 1-5$. https://doi.org/10.1097/IOP.0000000000000884

Cassetta, M., Altieri, F., Pandolfi, S., \& Giansanti, M. (2017). The combined use of computer-guided, minimally invasive, flapless corticotomy and clear aligners as a novel approach to moderate crowding: A case report. Korean Journal of Orthodontics, 47(2), 130-141. https://doi.org/10.4041/kjod.2017.47.2.130

Chrzan, R., Urbanik, A., Karbowski, K., Moskała, M., Polak, J., \& Pyrich, M. (2012). Cranioplasty prosthesis manufacturing based on reverse engineering technology. Med Sci Monit, 18(1), 1-6.

Ciocca, L., Marchetti, C., Mazzoni, S., Baldissara, P., Rosaria, M., Gatto, A., ... Tarsitano, A. (2015). Accuracy of fibular sectioning and insertion into a rapid-prototyped bone plate, for mandibular reconstruction using CAD-CAM technology. Journal of Cranio-Maxillofacial Surgery, 43(1), 28-33. https://doi.org/10.1016/j.jcms.2014.10.005

Egger, J., Gall, M., Tax, A., Muammer, U., Zefferer, U., Li, X., ... Chen, X. (2017). Interactive reconstructions of cranial 3D implants under MeVisLab as an alternative to commercial planning software. PLoS ONE, 37(3). https://doi.org/10.1371/journal.pone.0172694

Ejaz, F., Ryan, J., Henriksen, M., Stomski, L., Feith, M., Osborn, M., ... Frakes, D. (2014). Color-coded patient-specific physical models of congenital heart disease. Rapid Prototyping Journal, 20(4), 336-343. https://doi.org/10.1108/RPJ11-2012-0105

Fang, J., Liu, J., Wu, T., Lee, J.-W., \& Kuo, T.-H. (2013). Complex Facial Deformity Reconstruction With a Surgical Guide Incorporating a Built-in Occlusal Stent as the Positioning Reference. The Journal of Craniofacial Surgery, 24(3), 260-265. https://doi.org/10.1097/SCS.0b013e31828cbccc

FDA. (2018). Medical Application on 3D printing. Retrieved May 5, 2018, from https://www.fda.gov/MedicalDevices/ProductsandMedicalProcedures/3DPrintingofMedicalDevices/ucm500539.htm

Gil, R. S., Roig, A. M., Obispo, C. A., Morla, A., Pagès, C. M., \& Perez, J. L. (2015). Surgical planning and microvascular reconstruction of the mandible with a fibular flap using computer-aided design, rapid prototype modelling, and precontoured titanium reconstruction plates: A prospective study. British Journal of Oral and Maxillofacial Surgery, 53(1), 49-53. https://doi.org/10.1016/j.bjoms.2014.09.015

Goh, R. C. W., Chang, C. N., Lin, C. L., \& Lo, L. J. (2010). Customised fabricated implants after previous failed cranioplasty. Journal of Plastic, Reconstructive and Aesthetic Surgery, 63(9), 1479-1484. https://doi.org/10.1016/j.bjps.2009.08.010

Han, Q., Qin, Y., Zou, Y., Wang, C., Bai, H., Yu, T., ... Wang, J. (2017). Novel exploration of 3D printed wrist arthroplasty to solve the severe and complicated bone defect of wrist. Rapid Prototyping Journal, 23(3), 465-473. https://doi.org/10.1108/RPJ-01-2016-0005

Hatamleh, M. M., Yeung, E., Osher, J., \& Huppa, C. (2017). Novel treatment planning of hemimandibular hyperplasia by the use of three-dimensional computer-aided-design and computer-aided-manufacturing technologies. Journal of Craniofacial Surgery, 28(3), 764-767. https://doi.org/10.1097/SCS.0000000000003438

Hieu, L., Bohez, E., Sloten, J. V, Hung, L. T., Khanh, L., Zlatov, N., \& Trung, P. D. (2010). Integrated Approaches for Personalised Cranio-Maxillofacial Implant Design and Manufacturing. In IFMBE Proceedings 27 (pp. 1-4). Dang 


\section{5th International Conference On}

\section{Modern Approaches in SCIENCE, TECHNOLOGY \& ENGINEERING}

\section{9 - 31 August, 2019 Germany, Berlin}

Khoa:

Springer

International.

Retrieved

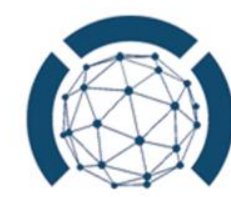

from

http://www.springerlink.com/content/t063g57072721m26/\%5Cnpapers2://publication/uuid/734D6264-9359-443C-

B929-11A4114DF4C7

Hussein, A. M. (2013). Evaluation of an innovative computer-assisted sagittal split ramus osteotomy to reduce neurosensory alterations following orthognathic surgery: a pilot study, (October 2012), 134-141. https://doi.org/10.1002/rcs

Ishengoma, F. R., \& Mtaho, A. B. (2014). 3D Printing : Developing Countries Perspectives. International Journal of Computer Applications, 104(11), 30-34.

Kanno, Y., Nakatsuka, T., Saijo, H., Fujihara, Y., Atsuhiko, H., Chung, U. Il, .. Hoshi, K. (2016). Computed tomographic evaluation of novel custom-made artificial bones, "CT-bone", applied for maxillofacial reconstruction. Regenerative Therapy, 5, 1-8. https://doi.org/10.1016/j.reth.2016.05.002

Kaur, H., Nanda, A., Koli, D., Verma, M., Singh, H., Bishnoi, I., ... Gupta, A. (2015). An Alternate Vista in Rehabilitation of Cranial Defects. Journal of Craniofacial Surgery, 26(4), 1313-1315. https://doi.org/10.1097/scs.0000000000001633

Kouhi, E., Masood, S., \& Morsi, Y. (2008). Design and fabrication of reconstructive mandibular models using fused deposition modeling. Assembly Automation, 28(3), 246-254. https://doi.org/10.1108/01445150810889501

Kozakiewicz, M., Elgalal, M., Loba, P., Komuński, P., Arkuszewski, P., Broniarczyk-Loba, A., \& Stefańczyk, L. (2009). Clinical application of 3D pre-bent titanium implants for orbital floor fractures. Journal of Cranio-Maxillofacial Surgery, 37(4), 229-234. https://doi.org/10.1016/j.jcms.2008.11.009

Lantada, A. D., \& Morgado, P. L. (2013). Introduction to Modern Product Development. In Handbook on Advanced Design and Manufacturing Technologies for Biomedical Devices (pp. 1-17). Springer International. https://doi.org/10.1007/978-1-4614-6789-2

Larsson, A., Törlind, P., Karlsson, L., Mabogunje, A., Leifer, L., Larsson, T., \& Elfström, B.-O. (2003). Distributed team innovation: A framework for distributed product development. In International Conference on Engineering Design (pp. 1-10).

Lavy, S., Garcia, J. A., \& Dixit, M. K. (2010). Establishment of KPIs for facility performance measurement: Review of literature. Facilities, 28(9), 440-464. https://doi.org/10.1108/02632771011057189

Logeart-Avramoglou, D., Anagnostou, F., Bizios, R., \& Petite, H. (2005). Engineering bone: challenges and obstacles. Journal of Cellular and Molecular Medicine, 9(1), 72-84. https://doi.org/009.001.08 [pii]

Maresova, P., Penhaker, M., Selamat, A., \& Kuca, K. (2015). The potential of medical device industry in technological and economical context. Therapeutics and Clinical Risk Management, 11, 1505-1514. https://doi.org/10.2147/TCRM.S88574

Martiínez, J., López, C., Murillo, A., \& Garnica, I. (2019). PLM Strategy for Developing Specific Medical Devices and Lower Limb Prosthesis at Healthcare Sector: Case Reports from the Academia. In Product Lifecycle Management (Volume 4): The Case Studies (4th ed., Vol. 4, pp. 201-222). Springer International. https://doi.org/10.1007/978-3-03016134-7

Mazzoni, S., Bianchi, A., Schiariti, G., Badiali, G., \& Marchetti, C. (2015). Computer-aided design and computer-aided manufacturing cutting guides and customized titanium plates are useful in upper maxilla waferless repositioning. Journal of Oral and Maxillofacial Surgery, 73(4), 701-707. https://doi.org/10.1016/j.joms.2014.10.028

McAllister, P., Watson, M., \& Burke, E. (2018). A Cost-Effective, In-House, Positioning and Cutting Guide System for Orthognathic Surgery. Journal of Maxillofacial and Oral Surgery, 17(1), 112-114. https://doi.org/10.1007/s12663-0171067-y

Mendez, B. M., Chiodo, M. V., \& Patel, P. A. (2015). Customized "in-office” three-dimensional printing for virtual surgical planning in craniofacial surgery. Journal of Craniofacial Surgery, 26(5), 1584-1586. https://doi.org/10.1097/SCS.0000000000001768

Mottini, M., Seyed Jafari, S. M., Shafighi, M., \& Schaller, B. (2016). New approach for virtual surgical planning and mandibular reconstruction using a fibula free flap. Oral Oncology, 59, e6-e9. https://doi.org/10.1016/j.oraloncology.2016.06.001 


\section{5th International Conference On}

\section{Modern Approaches in SCIENCE, TECHNOLOGY \& ENGINEERING \\ 29 - 31 August, 2019 Germany, Berlin}

Myung, S. (2018). Developing Key Performance Indicators for Shipbuilding PLM. In 15th International Conference on Product Lifecycle Management (pp. 1-14). Torino: Springer International.

Nasr, E. A., Al-Ahmari, A. M., Alkhawashki, H., Altamimi, A., \& Alkhuraisi, M. (2015). Developing a methodology for analysis and manufacturing of proximal interphalangeal (PIP) joint using rapid prototyping technique. Rapid Prototyping Journal, 21(4), 449-460. https://doi.org/10.1108/RPJ-11-2013-0118

Ngo, T., Belkadi, F., \& Bernard, A. (2017). Applying PLM approach for supporting collaborations in medical sector: case of prosthesis implantation. Advances on Mechanics, Design Engineering and Manufacturing, 871-878. https://doi.org/10.1007/978-3-319-45781-9

Ortiz, T., Tochetto, B., Thomazi, H., Quadrado, L., Gonzales, P., \& Novaes, A. (2012). Calcium Phosphate Cement in Orbital Reconstructions. J Craniofac Surg, 23(1), 145-148. https://doi.org/10.1097/SCS.0b013e3182413d31

Park, E. K., Lim, J. Y., Yun, I. S., Kim, J. S., Woo, S. H., Kim, D. S., \& Shim, K. W. (2016). Cranioplasty enhanced by three-dimensional printing: Custom-made three-dimensional-printed titanium implants for skull defects. Journal of Craniofacial Surgery, 27(4), 943-949. https://doi.org/10.1097/SCS.0000000000002656

Peel, S., \& Eggbeer, D. (2016). Additively manufactured maxillofacial implants and guides - Achieving routine use. Rapid Prototyping Journal, 22(1), 189-199. https://doi.org/10.1108/RPJ-01-2014-0004

Pinna, C., Galati, F., Rossi, M., Saidy, C., Harik, R., \& Terzi, S. (2018). Effect of product lifecycle management on new product development performances: Evidence from the food industry. Computers in Industry, 100(March), 184-195. https://doi.org/10.1016/j.compind.2018.03.036

Popescu, D., Ilie, C., Laptoiu, D., Hadar, A., \& Barbur, R. (2016). Web-based collaborative platform for personalized orthopaedic applications. Studies in Informatics and Control, 25(4), 517-526. https://doi.org/10.24846/v25i4y201613

Rahmati, S., Abbaszadeh, F., \& Farahmand, F. (2012). An improved methodology for design of custom-made hip prostheses to be fabricated using additive manufacturing technologies. Rapid Prototyping Journal, 18(5), 389-400. https://doi.org/10.1108/13552541211250382

Reiser, V., Alterman, M., Shuster, A., Kleinman, S., Shlomi, B., Yanko-Arzi, R., ... Fliss, D. M. (2015). V-stand - A versatile surgical platform for oromandibular reconstruction using a 3-dimensional virtual modeling system. Journal of Oral and Maxillofacial Surgery, 73(6), 1211-1226. https://doi.org/10.1016/j.joms.2014.12.033

Ruiz-Huerta, L., Almanza-Arjona, Y., \& Caballero-Ruiz, A. (2016). CAD and AM-fabricated moulds for fast craniomaxillofacial implants manufacture. Rapid Prototyping Journal, 22(1), 31-39. https://doi.org/10.1108/RPJ-03-20140032

Salonitis, K., \& Stavropoulos, P. (2013). On the integration of the cax systems towards sustainable production. Procedia CIRP, 9, 115-120. https://doi.org/10.1016/j.procir.2013.06.178

Santos, I. C., Gazelle, G. S., Rocha, L. a, \& Tavares, J. M. R. (2012). Medical device specificities: opportunities for a dedicated product development methodology. Expert Review of Medical Devices, 9(3), $299-311$. https://doi.org/10.1586/erd.12.3

Stark, J. (2016). Product Lifecycle Management. Product Lifecycle Management (Third Edit, Vol. 2). Geneva, Switzerland: Springer International. https://doi.org/10.1007/978-0-85729-546-0

Turgut, G., Özkaya, Ö., \& Kayal, M. U. (2012). Computer-aided design and manufacture and rapid prototyped polymethylmethacrylate reconstruction. Journal of Craniofacial Surgery, 23(3), 770-773. https://doi.org/10.1097/SCS.0b013e31824dbcaf

van Eck, N. J., \& Waltman, L. (2010). Software survey: VOSviewer, a computer program for bibliometric mapping. Scientometrics, 84(2), 523-538. https://doi.org/10.1007/s11192-009-0146-3

Wei, R., Guo, W., Ji, T., Zhang, Y., \& Liang, H. (2017). One-step reconstruction with a 3D-printed, custom-made prosthesis after total en bloc sacrectomy: a technical note. European Spine Journal, 26(7), 1902-1909. https://doi.org/10.1007/s00586-016-4871-z

WHO. (2003). Medical Device Regulation. Global Overview and guiding principles. World Health Organization (Vol. E2440.001.). Geneva. 


\section{5th International Conference On}

\section{Modern Approaches in SCIENCE, TECHNOLOGY \& ENGINEERING \\ 29 - 31 August, 2019 Germany, Berlin}

WHO. (2017). WHO Global Model Regulatory Framework for Medical Devices including in vitro diagnostic medical devices. Geneva. Retrieved from http://www.who.int/medicines/areas/quality_safety/quality_assurance/ModelregulatoryFramework-MedDev-QAS16664.pdf

Wong, K. C., Kumta, S. M., Gee, N. V. L., \& Demol, J. (2015). One-step reconstruction with a 3D-printed, biomechanically evaluated custom implant after complex pelvic tumor resection. Computer Aided Surgery, 20(1), 1423. https://doi.org/10.3109/10929088.2015.1076039

Xu, N., Wei, F., Liu, X., Jiang, L., Cai, H., Li, Z., ... Liu, Z. (2016). Reconstruction of the upper cervical spine using a personalized 3D-printed vertebral body in an adolescent with ewing sarcoma. Spine, 41(1), E50-E54. https://doi.org/10.1097/BRS.0000000000001179

Yang, W. fa, Choi, W. S., Leung, Y. Y., Curtin, J. P., Du, R., Zhang, C. yu, .. Su, Y. xiong. (2018). Three-dimensional printing of patient-specific surgical plates in head and neck reconstruction: A prospective pilot study. Oral Oncology, 78(November 2017), 31-36. https://doi.org/10.1016/j.oraloncology.2018.01.005

Zdravković, M., Trajanović, M., Stojković, M., Mišić, D., \& Vitković, N. (2012). A case of using the semantic interoperability framework for custom orthopedic implants manufacturing. Annual Reviews in Control, 36(2), 318-326. https://doi.org/10.1016/j.arcontrol.2012.09.013

Zhang, L., Shen, S., Yu, H., Shen, S. G., \& Wang, X. (2015). Computer-aided design and computer-aided manufacturing hydroxyapatite/epoxide acrylate maleic compound construction for craniomaxillofacial bone defects. Journal of Craniofacial Surgery, 26(5), 1477-1481. https://doi.org/10.1097/SCS.0000000000001410

Zhang, Y., Zhang, L., Sun, R., Jia, Y., Chen, X., Liu, Y., ... Feng, L. (2018). A new 3D printed titanium metal trabecular bone reconstruction system for early osteonecrosis of the femoral head. Medicine (United States), 97(26), 1-9. https://doi.org/10.1097/MD.0000000000011088

\section{Appendix I.}

Table 2: The Log review and research equation.

\begin{tabular}{|c|c|c|c|}
\hline No & Sub-research equation group & $\begin{array}{l}\text { WOS } \\
\text { results }\end{array}$ & $\begin{array}{l}\text { PubMed } \\
\text { results }\end{array}$ \\
\hline$\# 1$ & $\begin{array}{l}\mathrm{TS}=(\text { "3D print*" OR "3-dimension* print*" OR "3-D print*" OR "three dimension* print*" OR } \\
\text { "additiv* manufactur*" OR "AM" OR "additive technolog*" OR "rapid prototyp*" OR "RP" OR } \\
\text { "prototyp*3D print*" OR "desktop manufactur*" OR "desktop 3D print*") Data bases= WOS, KJD, } \\
\text { RSCI, SCIELO. Time period=2010-2018. Language=English }\end{array}$ & 150,774 & $\underline{1,596,013}$ \\
\hline \#2 & $\begin{array}{l}\text { TS=("manufact* capab*" OR "operat* capab*" OR "technolog* capab*" OR "manufact* } \\
\text { estrateg*" OR "product develop*" OR "conventional fabrication" OR "substrative manufact*" OR } \\
\text { "traditional technolog*" OR "CNC" OR "computer-integrated manufact*" OR "milling" OR "digital } \\
\text { fabrication" OR "direct digital manufact*" OR "CAD" OR "computer-aided design*" OR "manufact* } \\
\text { informat* system*" OR "stage*" OR "process*"OR "pre-process*" OR "post-process*") Data bases= } \\
\text { WOS, KJD, RSCI, SCIELO. Time period=2010-2018. Language=English }\end{array}$ & $4,835,004$ & $\underline{2,447,578}$ \\
\hline$\# 3$ & $\# 2$ AND \#1 & 39,445 & 116,716 \\
\hline$\# 4$ & $\begin{array}{l}\mathrm{TS}=(\text { "collaborat*" OR "collaborat* software" OR "collabor* work*" OR "collabor* strateg*" OR } \\
\text { "work* together" OR "collabor* framework" OR "collabor* model" OR "collabor* situation*" OR } \\
\text { "teamwork*" OR "joint effort" OR "cooperat*") Data bases= WOS, KJD, RSCI, SCIELO. Time } \\
\text { period=2010-2018. Language=English }\end{array}$ & 373,293 & 73,711 \\
\hline \#5 & $\begin{array}{l}\mathrm{TS}=(\text { "strateg*" OR "detail* plan*" OR "blueprint*" OR "itinerary" OR "long-range plan*" OR } \\
\text { "operat* strateg*" OR "guideline" OR "implement*" OR "PLM" OR "product lifecycle manage*" OR } \\
\text { "lifecycle phase*" OR "traceability" OR "data security" OR "role*" OR "action course*" OR "progress } \\
\text { monitor*") Data bases= WOS, KJD, RSCI, SCIELO. Time period=2010-2018. Language=English }\end{array}$ & $3,778,186$ & $2,583,251$ \\
\hline \#6 & $\begin{array}{l}\mathrm{TS}=(\text { "workflow" OR "digital workflow" OR "clinical decision mak*" OR "conventional } \\
\text { workflow" OR "wait* time*" OR "delivery" OR "best practice*" OR "engag* service*" OR "organiz* }\end{array}$ & $2,718,886$ & $3,379,536$ \\
\hline
\end{tabular}




\section{5th International Conference On}

Modern Approaches in SCIENCE,

\begin{tabular}{|c|c|c|c|}
\hline No & Sub-research equation group & $\begin{array}{l}\text { WOS } \\
\text { results }\end{array}$ & $\begin{array}{l}\text { PubMed } \\
\text { results }\end{array}$ \\
\hline & $\begin{array}{l}\text { process" OR "stage* process" OR "role" OR "role identi*" OR "actor*" OR "heterogene* expert*" OR } \\
\text { "specific NEAR/2 patient*" OR "radiologist*" OR "medical doctor*" OR "physician*" OR "plastic } \\
\text { surgeon*" OR "orthopedic surgeon*" OR "nurse*" OR "industrial engineer*" OR "industrial } \\
\text { designer*" OR "design engineer*" OR "manufacture engineer*" OR "quality engineer*" OR } \\
\text { "treatment process" OR "BMP" OR "business process model" OR "UML" OR "unified modeling } \\
\text { language" OR "flow chart" OR "delivery priority" OR "peer-to-peer" OR "P2P") Data bases= WOS, } \\
\text { KJD, RSCI, SCIELO. Time period=2010-2018. Language=English }\end{array}$ & & \\
\hline \#7 & $\begin{array}{l}\text { TS=("KPI" OR "key performance indicator*" OR "key performance parameter*" OR "key } \\
\text { characterist*" OR "health resource*" OR "health manpower" OR "performance employee" OR } \\
\text { "performance activit*" OR "performance process*" OR "measur*" OR "test*" OR "metric*" OR "rat*" } \\
\text { OR "measur* progress*" OR "measur* performance" OR "amount" OR "work* performance" OR } \\
\text { "device parameter*" OR "device key indicator*" OR "test* requirement*" OR "cost reduction" OR } \\
\text { "time reduction" OR "expect* time" OR "quantity of material" OR "available material" OR "custom } \\
\text { procedure" OR "quality control" OR "final comparison" OR "cleanliness" OR "damage check*" OR } \\
\text { "speed" OR "resolution" OR "accuracy" OR "reliability" OR "repeatability" or "smooth") Data bases= } \\
\text { WOS, KJD, RSCI, SCIELO. Time period=2010-2018. Language=English }\end{array}$ & $9,594,516$ & $4,132,607$ \\
\hline$\# 8$ & $\begin{array}{l}\text { TS=("Interoperab*" OR "health information exchang*" OR "health information system*" OR } \\
\text { "healthcare" OR "barrier*" OR "facilitator" OR "information storage" OR "health information } \\
\text { interoperab*" OR "health information system interoperab*" OR "technolog* integrat*" OR "product } \\
\text { data manag*" OR "neutral exchang*" OR "data shar*" OR "information shar*" OR "storage data" OR } \\
\text { "main data" OR "data access right*" OR "imag* data" OR "DICOM standard" OR "disease data" OR } \\
\text { "imaging data" OR "STL file*" OR "updat*" OR "synchroni*" OR "heterogeneous tool*") Data } \\
\text { bases= WOS, KJD, RSCI, SCIELO. Time period=2010-2018. Language=English }\end{array}$ & 938,392 & $1,270,238$ \\
\hline$\# 9$ & \#8 AND \#7 AND \#6 AND \#5 AND \#4 & 3,568 & 649 \\
\hline$\# 10$ & $\begin{array}{l}\text { TS=("trauma*" OR "wound*" OR "injur*" OR "external force" OR "structural disruption" OR } \\
\text { "continuity disruption" OR "bone fractur*" OR "rupture" OR "surgical" OR "orthopedic" OR } \\
\text { "arthroplasty" OR "severe injur*" OR "violent attack" OR "accident" OR "damage" OR "harm") Data } \\
\text { bases= WOS, KJD, RSCI, SCIELO. Time period=2010-2018. Language=English }\end{array}$ & $2,086,851$ & $2,438,294$ \\
\hline$\# 11$ & $\begin{array}{l}\text { TS=("medical device*" OR "device performance" OR "economic evaluation" OR "technology } \\
\text { assessment" OR "device performance" OR "device quality" OR "custom* device" OR "personal* } \\
\text { device" OR "tailored device" OR "requirement accompli*" OR "biocompatib*" OR "time reduc*" OR } \\
\text { "safety" OR "efficacy" OR "effectiveness" OR "aesthetic" OR "recovery time" OR "post-surgery" OR } \\
\text { "blood loss" OR "steril* material" OR "compliance") Data bases= WOS, KJD, RSCI, SCIELO. Time } \\
\text { period=2010-2018. Language=English }\end{array}$ & $1,860,793$ & $2,191,233$ \\
\hline$\# 12$ & $\begin{array}{l}\text { TS=("Specific Medical devices" OR "pre-surgical planning device" OR "educati* device*" OR } \\
\text { "biomodel device" OR "cut* guide*" OR "surgical guide*" OR "implant" OR "patient-specific } \\
\text { implant" OR "PSI" OR "surgical tool*" OR "prosthetic" OR "temporary prosthesis" OR "3D print* } \\
\text { medical device" OR "non-3D-print* medical device" OR "anatomical model*" OR "segment*" OR } \\
\text { "relevant region" OR "osteotomy alignment ") Data bases= WOS, KJD, RSCI, SCIELO. Time } \\
\text { period=2010-2018. Language=English }\end{array}$ & 419,302 & $1,628,573$ \\
\hline$\# 13$ & \#12 AND \#11 AND \#10 & 17,810 & 65,385 \\
\hline$\# 14$ & \#13 AND \#9 AND \#3 & 0 & 1 \\
\hline$\# 15$ & \#13 AND \#3 & 192 & 466 \\
\hline$\# 16$ & \#13 AND \#9 & 3 & 4 \\
\hline$\# 17$ & \#9 AND \#3 & 11 & 20 \\
\hline$\# 18$ & \#17 OR \#16 OR \#15 & 206 & 488 \\
\hline$\# 19$ & $\begin{array}{l}\text { (((\#14) OR \#15) OR \#16) OR \#17 AND ("2008/09/07"[PDat] : "2018/09/04"[PDat] AND } \\
\text { "humans"[MeSH Terms] AND English[lang]) }\end{array}$ & - & 236 \\
\hline
\end{tabular}

Source: By Authors. Sub-research equation were written like this: "TS=(...)” defined for Web Of Science, and "search(...)" for PubMed. Filters used in both were showed in italic. 